International Journal of English Literature and Social Sciences
Vol-7, Issue-1; Jan-Feb, 2022
Journal Home Page Available: https://ijels.com/
Journal DOI: $10.22161 / \mathrm{ijels}$

Peer-Reviewed Journal

\title{
Comprehending surface reading through The Fly
}

\author{
Nandhitha M
}

Graduate student, Department of English, National Institute of Technology -Tiruchirapalli

Email: nandhithaofficial@gmail.com; ORCID ID: https://orcid.org/0000-0002-4358-7249

Received: 25 Nov 2021; Received in revised form: 18 Jan 2022; Accepted: 24 Jan 2022; Available online: 31 Jan 2022

(C)2022 The Author(s). Published by Infogain Publication. This is an open access article under the CC BY license

(https://creativecommons.org/licenses/by/4.0/).

\begin{abstract}
Surface reading is a lesser-used yet effective method of critical reading. The more commonly practiced method of symptomatic reading focuses on unearthing meaning from a depth that texts supposedly hide on the surface. On the contrary, surface reading positions all interpretations of the text on its surface itself. The text presents all its interpretations through its verbal structure, critical descriptions, patterns, et al. Renowned short story writer Katherine Mansfield's works present best interpretations best when surface reading is employed. She connects themes, characters and textual content in an intricately and carefully designed web on the surface. In particular, her short story - 'The Fly' - is a classic case where methods of surface reading as a verbal structure of language, critical descriptions, patterns that exist across and within text(s), et al. can be studied exhaustively. This article elucidates the benefits and techniques of surface reading through a case study of Mansfield's 'The Fly'.
\end{abstract}

Keywords - surface reading, symptomatic, ideology, interpretation, criticism.

\section{INTRODUCTION}

The most commonly practiced method of critical reading in literature is symptomatic reading. Right from school classrooms, one is first expected to read up on the sociopolitical and cultural "background" of a text, the author's biography and the underlying themes; only then is the text opened for perusal. The interpretation of the text is thus narrowed down to a few ideological constructs and contexts. Textual analysis tends to be perceived through ideological lenses, owing to the rise of various ideological movements in the $20^{\text {th }}$ century (Best and Marcus, 2009). Sadly, texts are even chosen to be taught and read critically based upon their conformism to particular ideologies as found by critics, who crown them as the 'canonical texts' of a representative ideology. Texts thus become mere examples of a particular agenda.

Strangely, symptomatic reading is not the norm when reading is done for pleasure. Readers do not adorn the role of detectives who suspiciously view the text as an object of deception. There is no prior study of authorial intention and contexts made. Readers accept or refute what the text intends to communicate on its surface. Interestingly, such interpretations of a text are not purely unique. Often, interpretations are shared and similar among many readers of the same text. A text can, hence, have plural meanings, but neither can it have infinite meanings beyond its scope (Belsey, 2013) nor a single, ideologically restrained meaning. This calls back to Best and Marcus' observations about "surface reading" (2009, p. 9) - a method that this essay will attempt to identify as a beneficial and viable reading method vis-à-vis The Fly.

\section{CONTEXTUALIZATION IN SYMPTOMATIC READING}

The Fly is a short story by Katherine Mansfield that explores the psyche of an unnamed "boss" in conversation with his former employee, Mr.Woodifield. The story has intrigued many readers, for the story spans only about two thousand words, has an office setting and just two pivotal characters present. Mansfield conveys deep emotional content within this space and establishes parallels between dominance and toxic emotional restraint; grief and stoicism; exuberance and dullness. The work naturally sprung various critiques that attempted to unearth what the 
story conceals beneath its surface and supposedly protests to reveal. For such revelation, a popular tool used is placing the story within its historical context, especially in tandem with the author's biography.

In Mansfield's case, such unearthing does reveal a plethora of additional information:

“...in 1915, when Mansfield received the news that her brother had been killed fighting in France...When her mother died in 1919, she described her banker father's reaction thus: 'Of course he had money, but it makes no difference to him. He falls into absolute pits of depression and loneliness." (Hagopian, 1963, p. 385)

Early critics of The Fly have interpreted the characters of the boss' son and the boss to correspond to the author's family members, as described in the aforementioned excerpt. Such multiple symbolic assumptions about characters resulted in the text being declared as a failure by Sylvia Berkman. She observed that "the central symbolism is confused." (Berkman, 1951 qtd. as cited in van Gunsteren, 1990, 230). She surmised that Mansfield's reading of King Lear shortly before penning the short story was the plausible reason behind the boss' torture of a mere fly. Similarly, her struggle with tuberculosis and eventual death at the hands of the disease were read as analogous to the fly's life-and-death situation in the hands of the boss. Nonetheless, she found the assumed symbolisms about the family confusing, owing to the boss' personal sufferings being juxtaposed with his egotistical cruelty. (Hagopian, 1963, pp. 385-386).

Symptomatic reading tends to lead towards such crossfire as seen above. The suspicion of a "covert progression of the plot" (Shen, 2013) that the text veils from interpretation led to the unfair decreeing of this work as a failure. In positioning the text as an obstacle that hides truths, it can be witnessed that:

"Context is, in this sense, an endlessly contested concept, subject to often rancorous rehashing and occasional bursts of sectarian sniper fire.” (Felski, 2011, p. 573)

The search for historical contexts and authorial intentions in a text is indeed beneficial for holistic reading. The challenge arises in positioning the text as an inert surface from which meaning, hidden at a depth, has to be wrenched out or forcefully inserted (Best and Marcus, 2009). What critics with a symptomatic reading approach fail to see is that the text lays out elements that help procure these deep meanings on its surface itself.

\section{APPLICATION OF SURFACE READING TECHNIQUES IN THE FLY}

\subsection{Verbal structure}

The Fly conveys rich and comprehensible meaning through surface reading. For instance, Woodifield is depicted as a weak man even before his boss' dominance is exerted on him. Mansfield cleverly illustrates Woodfield's dependency and frailty by comparing him to a baby:

"...he peered out of the great, green-leather armchair by his friend the boss's desk as a baby peers out of its pram." (Mansfield, 1922/2007, p. 406).

The image continues when Woodifield is depicted as dependent on the women in his family, much like infants. Additionally, the ellipsis between "his" and "stroke" (Mansfield, 1922/2007, p. 406) clearly indicates the pause in Woodifield's life that the disorder has created. Through a close reading of the punctuations, words and comparisons, the form of the text lends itself to interpretations. Surface reading hence observes closely the "intricate verbal structure of literary language" (Best and Marcus, 2009, p. 10) to elicit meaning.

Verbal structures further reveal the dialectics of dominance between Woodifield and the boss. A notable instance is in Woodifield's recollection that his family had visited the boss' son's grave. Interestingly, a close reading of the surface becomes beneficial in determining Woodifield's pivotal assertion of agency here. The only point wherein he mobilises his agency is brilliantly depicted via his own mobility:

“"That was it,' he said, heaving himself out of his chair." (Mansfield, 1922/2007, p. 408)

It is only through reading the surface as an "intricate verbal structure of language" (Best and Marcus, 2009, p. 10) that we notice the lone instance of Woodifield's agency; a key occurrence that reveals the cause of the boss' emotional indifference. Mansfield's style of narration across her oeuvre carries a detailed verbal structure that often helps in interpreting her ideas on the surface of the text itself.

\subsection{Critical descriptions}

The tension for dominance between the boss and Woodifield is well established through descriptions. Woodifield's jealousy of his boss' prosperity and the narcissist boss' resultant pleasure in exerting dominance upon the weak, former employee is seen in the critical description used here:

"So there sat old Woodifield, smoking a cigar and staring almost greedily at the boss, who rolled in his office chair, stout, rosy, five years older than he, and still going strong, still at the helm...As a matter of fact he was proud of his room; he liked to have it admired, especially by old 
Woodifield. It gave him a feeling of deep, solid satisfaction to be planted there in the midst of it in full view of that frail old figure in the muffler." (Mansfield, 1922/2007, p. 406)

The boss' apathy becomes evident when he schedules time to unwind his deep grief but fails to weep. The description of his scheduled grief intervals and futile attempts to cry excellently execute the rendering of his character. The interpretation becomes clear that grief, which is natural, feels foreign to him because he "wanted to feel" strong and dominant:

"The boss took his hands from his face; he was puzzled. Something seemed to be wrong with him. He wasn't feeling as he wanted to feel." (Mansfield, 1922/2007, p. 409)

Quite immediately after he understands his emotional instability, the titular fly appears. The boss' mistreatment of the fly is again an instance of critical description. His actions shift between finding joy in seeing the fly "ready for life again" (Mansfield, 1922/2007, p. 410) But simultaneously, he enjoys testing the fly's endurance by dropping ink on it, crushing it to its earlier fate. Neverthelesss, he quickly follows this action by breathing onto the insect and drying its wings. Noticeably, he demands the fly to be quick about its resurrection, just as he orders Macey around:

"“Come on,' said the boss. 'Look sharp!"” (Mansfield, 1922/2007, p. 411)

Critical description plays a significant role in textual interpretation through surface reading here. Having been introduced to the boss' domineering quality and the cause of his emotional indifference, the fly can be read as an embodiment of his own tragic state without external tools of literary criticism. The miserable circumstances of his life pushed him to exert dominance as a cover for his emotional numbness. The authoritarian role he performs hence can be viewed as self-inflicted mental torture that unfortunately ends up in his apathetic nature.

\subsection{Patterns within and across texts}

The boss' domineering nature can further be traced from various other instances throughout the text as a network of "patterns that exist within texts" (Best and Marcus, 2009, p. 11). One such pattern of domination is in names, or the lack thereof. The boss rarely refers to anyone by their actual name. His son is never addressed by name; the fly becomes a "little beggar", and Macey is reduced to a "dog" - a loyal servant who follows its master's orders obediently. Even his former employee becomes "old" Woodifield, despite being five years younger than him. His own name remains unrevealed; only his role of a dominating "boss" is portrayed. Likewise, the fly and
Macey are expected to "look sharp" and be quick about their work. This pattern of names and repetitive phrases hence reveals to the readers much about the character without assuming any contextual information. The interpretation is independent of a surface-depth hierarchy between the text and the context.

Moreover, the boss' apathy can be read as a "pattern across texts" (Best and Marcus, 2009, pg. 11). Mansfield's narration usually shifts between a glimpse into her characters' thoughts and back into a third person narration omnipresent narration. A similar pattern can be seen in her narration technique in The Fly, where readers know what the boss and Woodifield are thinking but also, are left to discover more information from the events that are presented in narration. A classic example of a character, away from Mansfield's oeuvre, whose need for dominance is hinted at through peeks into their psyche is of the Duke of Ferrara in My Last Duchess. The Duke is deluded in his own need to exert control and power that the innocent acts of the duchess prove to be fatal to her. This pattern can be seen in the boss' self-deluded nature. The narrative techniques of both works are also alike. Such parallels that exist across texts and within texts are devoid of ideological constraints. This reveals that texts have visible and coherent patterns of meaning on the surface itself and do not need to be excavated from beneath the text.

\section{CONCLUSION}

Throughout this textual analysis, there were no hierarchical placements between the text and context or between the form and the content. Nor were ideological references, socio-political backgrounds or the author's biographical study used to support interpretations. Surface reading encourages such interpretations that stem from the text rather than from its agenda (Belsey, 2013). By assuming a depth where latent meaning hides under the surface, an ideological framework arises that restricts the text from expressing what it truly means. This further negates the possibility of a text surviving trans-temporally (Felski, 2011); only a fixed canon that conforms to ideological frameworks can survive. For instance, in surface reading The Fly, much about the characters and the plot was comprehensible from the critical description employed, the patterns they drew within and across texts and the intricate verbal structures present. If the context of the author's biography was placed as a "depth" where meaning lies, the primary interpretation made would have been that the text is an allegorical retelling of the tragic instances in the author's life. The interpretation would thus have been locked within the author's biographical context alone. 
Evidently, surface reading allows for the most beneficial form of reading in inviting original interpretations without any fixed, preconceived expectations from the text. There are a plethora of methods in which surface reading can be practiced apart from those elaborated in this essay. This widens the scope of approaches to literary criticism, alongside pleasurable reading. In symptomatic reading, the critical exercise is largely dependent on the need for some ideological or symbolic revelation. This pressure to unearth is nullified in surface reading, wherein patterns, descriptions and verbal structure naturally reveal themselves on the surface of the text. Surface reading thus ensures pleasurable reading as well.

This does not endorse the negation of contexts altogether. The text and the form it presents itself in must be addressed first. This allows for broader and interpretations, independent of contextual biases. Contexts identified in symptomatic reading can be used to eliminate implausible interpretations and add additional possibilities of meaning in a text after the suggested initial interpretative process. Surface reading enables this inclusive model of interpretation by neither pushing the text nor context to the background or the foreground, but considering them as a "constellation of multiple surfaces" (Cheng, 2009). Surface reading thus indicates hope for a holistic critical approach in literary criticism.

\section{REFERENCES}

[1] Belsey, C. (2013). Textual analysis as a research method. In G. Griffin (Ed.), Research Methods for English Studies (pp. 160-178). Edinburgh University Press.

[2] Best, S., \& Marcus, S. (2009). Surface Reading: An Introduction. Representations, 108(1), 1-21. https://doi.org/10.1525/rep.2009.108.1.1

[3] Cheng, A. A. (2009). Skins, Tattoos, and Susceptibility. Representations, 108(1), 98-119. https://doi.org/10.1525/rep.2009.108.1.98

[4] Felski, R. (2011). "Context Stinks!" New Literary History, 42(4), 573-591. https://doi.org/10.1353/nlh.2011.0045

[5] Hagopian, J. T. (1963). Capturing Mansfield's "Fly." Modern Fiction Studies, 9(4), 385-390. http://www.jstor.org/stable/26278733.

[6] Mansfield, K. (2007). The Fly. In The Collected Stories of Katherine Mansfield (pp. 408-411). Penguin Books. Originally published 1922.

[7] Shen, D. (2013). Covert Progression behind Plot Development: Katherine Mansfield's 'The Fly'. Poetics Today, 34(1-2), 147-175. https://doi.org/10.1215/03335372-2017276.

[8] van Gunsteren, J. (1990). Katherine Mansfield and Literary Impressionism. Rodopi. 